\title{
Mendel y el Neodarwinismo
}

\author{
Rommel Montúfar G. \\ Escuela de Ciencias Biológicas de la Pontificia Universidad Católica del Ecuador. \\ rjmontufar@puce.edu
}

Charles Robert Darwin nace en 1089, en el seno de una familia aristócrata del poblado inglés de Shrewsbury, cerca de la frontera con País de Gales. Su padre fue un reconocido médico local (Robert W. Darwin); su madre, Susana Wedgwood, fue hija de un afamado ceramista y miembro de la Royal Society. Entre 1825 y 1827 , Charles Darwin inicia sus estudios de medicina en la Universidad de Edimburgo, no los culmina debido a su falta de interés. Posteriormente, en 1828, ingresa a la carrera eclesiástica en el Colegio de Cristo de la Universidad de Cambridge, decisión razonable debido a que los naturalistas de la época en Inglaterra eran sacerdotes anglicanos.

En 1831, y a los 22 años de edad, Darwin es recomendado por el botánico y sacerdote anglicano J. S. Henslow para integrar la tripulación del H.M.S. Beagle (Keith, 1943). Después de numerosos años de estudios, recopilación, ordenamiento e interpretación de las colecciones, Darwin publica en 1859 la primera edición del libro The origen of species. En esta obra, Darwin propone una teoría para explicar la evolución de la vida estructurada en tres componentes:

1. Según Darwin, la base de la evolución biológica es la existencia de variabilidad individual o factor productivo; sin embargo, él reconoce su ignorancia para explicar las complejas leyes que regulan la creación de la variabilidad.

2. El segundo componente o factor selectivo manifiesta que si estas variaciones son provechosas para la supervivencia del individuo, serán heredadas por la descendencia a través de la selección natural. Los individuos con variaciones no provechosas tendrán menos posibilidades de supervivencia.

3. El tercer componente constituye una síntesis de los dos anteriores, Darwin acuña la palabra evolución para nombrar a su teoría y manifiesta que las especies no son inmutables, sino que una especie desciende directamente de otra especie.

Con estos tres componentes, Darwin estructura su teoría para explicar la evolución de las especies y de la vida; sin embargo, esta teoría adolece de un aspecto importante: los factores involucrados en la creación de la variabilidad no fueron explicados. Después de 1859, año de la publicación The origen of species, la discusión en las esferas científicas fue dirigida a las temáticas de la selección natural y evolución, conceptos que en esa época eran más fáciles de visualizar que los factores involucrados en crear variabilidad. 
¿Cómo se crea la variabilidad individual en las especies y qué leyes o reglas la regulan? Hasta el día de su muerte (1882), Darwin no pudo explicar los factores involucrados en la creación de la variabilidad, y consecuentemente la base de la teoría de la evolución tuvo un punto débil (Darwin, 2007).

Trece años después del nacimiento de Darwin (1822), en un pequeño pueblo de la frontera norte de lo que en ese entonces era el Imperio Austro-Húngaro (actualmente República Checa), nace en un hogar campesino Johann Mendel. Privado de recursos económicos y con problemas familiares, se ve obligado a ingresar como novicio al monasterio de los Agustinos en la localidad de Bruenn en 1843 , en donde adquiere el nombre de Gregor Mendel. Durante su permanencia en el monasterio, Mendel se destaca como un gran investigador $\mathrm{y}$ adquiere fama entre los estudiantes del monasterio, y en 1851 obtiene su doctorado en Matemáticas y Ciencias en la Universidad de Viena. Durante 1856 y 1866, Mendel se dedica al estudio de la hibridización de plantas llegando a analizar más de 10000 especímenes de hibridación. En febrero de 1865, Gregor Mendel leyó el artículo de su autoría titulado "Experiments on Plant Hibridization" frente a un grupo de sobresalientes investigadores y estudiantes de la Sociedad de Ciencias Naturales de Bruenn. Las minutas de esta reunión reportan que Mendel expuso su documento por más de una hora, en él describió los resultados de sus experimentos de hibridización realizados durante ocho años en el monasterio. Al final de su exposición no hubo preguntas ni discusión y la audiencia se dispersó demostrando falta de interés en los resultados de Mendel.

El documento de Mendel "Experiments on Plant Hibridization" fue publicado en 1866 en los Proceedings of the Society of Bruenn, siete años después de la primera edición de The origen of species de Darwin. El documento de Mendel fue enviado a numerosas sociedades de ciencias, universidades y especialistas de hibridización en Europa; sin embargo, su investigación no fue valorada científicamente. Hasta la fecha de su fallecimiento (1884), Mendel fue ignorado por el ámbito científico, e incluso el mismo no comprendió la magnitud de su descubrimiento (Iltis, 1943).

Treinta y cuatro años después de la publicación del trabajo de Mendel, y de forma coincidencial, tres investigadores, en tres diferentes lugares de Europa, DeVries en Amsterdam, Correns en Alemania y Tschermak en Viena, redescubren los trabajos de Mendel. W. Batenson en 1902 expone Los principios Mendelianos de la herencia en la Sociedad de Horticultura de Londres, en donde defiende los principios descritos por Mendel. W. Batenson reinterpreta los resultados de Mendel en tres leyes o reglas para explicar la herencia (ley de la uniformidad, de segregación y de la segregación independiente) y la variabilidad de los individuos (Wright, 1960).

Las investigaciones de Mendel constituyen el inicio de la ciencia de la genética. Conceptos y mecanismos que hoy conocemos, gracias a la biología celular, como la meiosis, el gen y el alelo, fueron descritos tempranamente en el documento "Experiments on Plant Hibridization" como segre- 
gación, entes de naturaleza desconocida e inmutable, y caracteres heredados, respectivamente. Adicionalmente, Mendel introdujo los conceptos de caracteres dominantes y recesivos, y su investigación es el inicio de la biología experimental y estadística. Las leyes, conceptos y mecanismos que aporta el pensamiento mendeliano son la base del desarrollo de disciplinas como la genética de poblaciones y la genética moderna. Pero fundamentalmente, las leyes de Mendel fueron los factores que Darwin ignoraba, y que son los generadores de la variabilidad genética de la teoría de la Evolución. A partir de 1902, cuando las leyes mendelianas fueron redescubiertas por W. Batenson, se convirtieron en una de las bases estructurales de la teoría de la Evolución; la síntesis del pensamiento Darwiniano y Mendeliano es lo que conocemos hoy en día como Neodarwinismo (Wright, 1960).

Los trabajos de Charles Darwin y Gregor Mendel constituyeron el inicio de la biología moderna. El primero fue un magnífico naturalissta y audaz observador que vivió en Londres, la capital intelectual y económica del mundo durante la Época Victoriana. Darwin fue ampliamente reconocido en el ámbito científico y supo aprovechar esta posición para defender y difundir su teoría. El segundo fue un sobresaliente biólogo experimental que residió en un recóndito monasterio de una localidad de Europa Central. El trabajo de Mendel no fue valorado en vida y murió en el anonimato científico. Darwin y Mendel fueron contemporáneos en la Europa del siglo XIX; es probable que Darwin nunca conociera del trabajo de Mendel o quizás no lo comprendió como lo hicieron muchos científicos en Europa. Lo cierto es que Darwin hizo preguntas que no pudo contestar, y Mendel respondió preguntas que ni él conocía.

\section{BIBLIOGRAFÍA}

Darwin, Ch. 2007. El origen de las especies. $23^{\mathrm{a}}$ edición, EDAF, México.

Iltis, H. 1943. Gregor Mendel and his work. En: A treasury of Science (Sharpley, H., Rapport, S.,Wright, H., editors). Harper \& Brothers publishers, Nueva York.

Keith, A. 1943. Darwin and "The origin of species". En: A treasury of Science (Sharpley, H., Rapport, S.,Wright, H., editors). Harper \& Brothers publishers, Nueva York. Wright, S. 1960. Genetics and Twentieth Century Darwinism--A review and discussion. American Journal of Human Genetics 12(3): 365-72.

Compilación y edición: Dr. Oswaldo Báez Tobar.

Revisión y corrección de estilo: Dr. Alberto B. Rengifo A. 